\title{
Intravitreal bevacizumab in macular edema secondary to branch retinal vein occlusion: 12-month results
}

This article was published in the following Dove Press journal:

Clinical Ophthalmology

II July 2012

Number of times this article has been viewed

\author{
Raba Thapa' \\ Nhukesh Maharjan² \\ Govinda Paudyal' \\ 'Vitreo-retinal Service, Tilganga \\ Institute of Ophthalmology, ${ }^{2}$ Research \\ Department, Tilganga Institute of \\ Ophthalmology, Kathmandu, Nepal
}

Video abstract

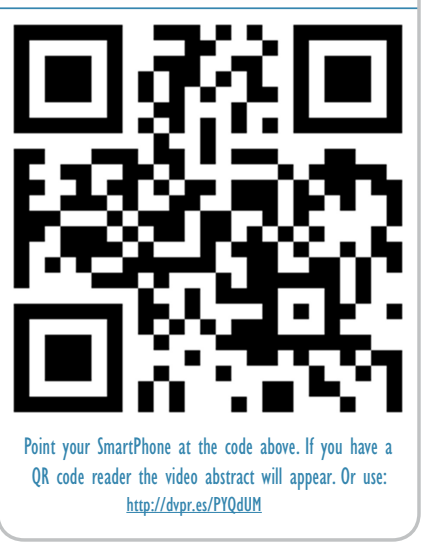

Correspondence: Raba Thapa

Vitreo-retinal Service, Tilganga Institute

of Ophthalmology, PO Box 56I,

Kathmandu, Nepal

Tel +977 | 4493775

Fax+977 I 4474937

Email rabathapa@live.com
Purpose: The purpose of this study was to evaluate the long-term safety, anatomical, and visual outcomes following intravitreal bevacizumab (Avastin; Genentech) on macular edema (ME) secondary to branch retinal vein occlusion (BRVO).

Methods: A prospective, interventional case series study was conducted among patients with ME due to BRVO, from June 2008 to October 2011. Intravitreal bevacizumab (1.25 mg/0.05 mL) was given at 4-6 weekly intervals until the ME subsided, and cases were followed up for a year. Complete ophthalmic evaluations and measurement of central retinal thickness (CRT) by optical coherence tomography were performed at baseline and follow-up visits.

Results: Sixty-three eyes of 63 patients were included in the study. The mean age was 58.22 years (standard deviation [SD], 12.3). The CRT at baseline was $515.3 \pm 189.4 \mu \mathrm{m}$, and it significantly improved at each follow-up, with a CRT of $233.6 \pm 101.5 \mu \mathrm{m}$ at 12 months. The best-corrected visual acuity (BCVA) at baseline was $0.82 \pm 0.54$, and it significantly improved at each follow-up, with a BCVA of $0.40 \pm 0.25$ at 12 months $(P<0.001)$. The BCVA was better in $76 \%$ of the patients with a more than three-line increase in $55.5 \%$ of the eyes. The average number of intravitreal bevacizumab injections was 3.1 (range, 1-6 injections). Recurrent ME occurred in $30.2 \%$ of cases. There were no major ocular or systemic adverse events.

Conclusion: Intravitreal bevacizumab appears to be a safe and effective drug for reducing ME and improving visual acuity secondary to BRVO at 12-month follow-up at a tertiary referral eye hospital in Nepal.

Keywords: branch retinal vein occlusion, bevacizumab, macular edema

\section{Introduction}

Retinal vein occlusion (RVO) is a common retinal vascular problem that is second in incidence only to diabetic retinopathy. Many risk factors have been associated with RVO, including age, hypertension, diabetes mellitus, atherosclerotic retinal vascular change, open angle glaucoma, and hypermetropia. ${ }^{1-3}$ Branch retinal vein occlusion (BRVO) is a type of RVO with potential sight-threatening complications. Macular edema (ME) is often the cause of visual problems in BRVO, and the most common complication of BRVO is the development of cystoid macular edema with a consecutive deterioration in vision. Macular grid laser is a proven treatment modality for reducing ME related to BRVO, but the Branch Vein Occlusion Study has shown a significant visual benefit only in persons with visual acuity of 20/40 or less, compared with the untreated control group. ${ }^{4}$ Several studies have shown positive results with intravitreal steroids in reducing $\mathrm{ME}$ and improving vision in patients with BRVO, but its use has been limited due to side effects, such as cataract formation and increased intraocular pressure. ${ }^{5,6}$ 
Vascular endothelial growth factor (VEGF) is a cytokine produced by the hypoxic retina that increases vascular permeability, which leads to ME. VEGF also stimulates endothelial cell hypertrophy, which reduces the capillary lumen and causes more ischemia, thus perpetuating the edema. ${ }^{7}$ Anti-VEGF treatment could break this cycle and facilitate resolution of ME. Bevacizumab (Avastin; Genentech Inc, San Francisco, CA) is a monoclonal antibody that inhibits all isoforms of VEGF. Its use for RVO was first reported by Rosenfeld in $2005 .{ }^{8}$ Since then, many case series have been published with better anatomical and visual success in reducing ME secondary to RVO, but they have been limited to developed countries. This prospective clinical study was designed to assess the long-term safety and efficacy of intravitreal bevacizumab and grid laser in selected cases of ME secondary to BRVO at a hospital in Nepal, a developing country with very limited resources.

\section{Materials and methods}

This prospective, interventional, nonrandomized, case series study was conducted at Tilganga Institute of Ophthalmology, a tertiary eye care center in Nepal. Consecutive cases of BRVO with ME, central retinal thickness (CRT) $>249 \mu \mathrm{m}$, and visual acuity worse than $6 / 12$, who could come for regular follow-up visits were invited to participate in the study. The study was conducted from July 2008 until September 2011. Patients excluded from the study were those with a history of treatment with laser therapy or intravitreal injections, age-related macular degeneration, diabetic retinopathy, macular scar, pre-existing glaucoma, or neovascular glaucoma secondary to RVO. Patients with uncontrolled hypertension, diabetes mellitus, myocardial infarction, or cerebrovascular accident within three months of presentation also were excluded. Informed consent was obtained from the patients before enrollment in the study, after fully explaining the possible risks and benefits of intravitreal bevacizumab. Ethical approval was obtained from the Institutional Review Board of the Institute, and the study was conducted according to the tenets of the Declaration of Helsinki.

A detailed history was taken to ascertain each patient's demographics and chief complaints, including duration of the problem and presence of systemic diseases, such as hypertension, diabetes mellitus, cardiac diseases, and hyperlipidemia.

Ocular evaluation included presenting and best-corrected visual acuity (BCVA) on a Snellen chart and anterior and posterior segment examinations using a Haag-Streit slitlamp and $90 \mathrm{D}$ lens, as well as an indirect ophthalmoscope and a $20 \mathrm{D}$ lens. Color fundus photography documented the affected regions of the retina. Fundus fluorescein angiography was not performed routinely in our series.

Central retinal thickness was assessed objectively with optical coherence tomography (Stratus OCT; Carl Ziess Meditec, Dublin, CA) at baseline and at every follow-up visit, at 4-6 weeks intervals, until the ME subsided, and then every 2-3 months until 12 months of follow-up were completed. Intraocular pressure was taken by Goldman applanation tonometry. Systemic blood pressure was measured at baseline and at each follow-up visit. Fasting and postprandial blood sugar and lipid panels were recommended in all cases to search for underlying systemic risk factors and to assess the level of metabolic control before intravitreal injection. Likewise, patients were advised to consult their physician and/or cardiologist for evaluation and control of systemic diseases.

The intravitreal bevacizumab was injected in a dose of $1.25 \mathrm{mg} / 0.05 \mathrm{~mL}$ through the pars plana with a $27 \mathrm{G}$ or $30 \mathrm{G}$ needle, at baseline and repeated at 4-6-week intervals, until the ME subsided. The intravitreal injections were administered aseptically in the operating theater. Afterwards, patients used a topical antibiotic (ciprofloxacin) four times a day and ciprofloxacin ointment at bedtime for a week. Detailed ophthalmic evaluation was performed at each follow-up including visual acuity, anterior and posterior segment evaluation, and assessment of ME. Recurrent ME was defined as any increase in central macular thickness (CMT) relative to the previous follow-up values. Retreatment with intravitreal bevacizumab was indicated in recurrent cases whenever the CMT increased $100 \mu \mathrm{m}$ or more, with or without vision deterioration of at least one line (five ETDRS letters). In such cases, if there was a presence of exudates, grid laser was also used along with the intravitreal bevacizumab. Recurrent ME cases with CMT less than $100 \mu \mathrm{m}$ from the previous follow-up value were treated with grid laser only, but only observed such cases if there were no exudates. Visual acuity was converted to LogMAR for visual outcome analysis. The data was analyzed in SPSS software (version 11.5; SPSS Inc, Chicago, IL). Paired $t$-tests were used for statistical analysis. $P$ values less than 0.05 were considered statistically significant in this study.

\section{Results}

A total of 63 eyes of 63 patients were included in the study. The mean age was 58.22 years (12.39 SD), with a range of 28-79 years. Males outnumbered females, comprising 57\% and $43 \%$ of the population, respectively. The mean duration of symptoms prior to presentation was 2.8 months (1.8 SD), 
with a range of two weeks to six months. The average number of intravitreal bevacizumab injections was 3.1 (1 SD), with a range of 1-6 (Table 1). Forty-one eyes had superotemporal BRVO, 19 eyes had inferotemporal BRVO, and three eyes had macular BRVO. Concurrent systemic hypertension was found in 31 cases (48\%), and nine patients (14.2\%) had diabetes mellitus.

\section{Follow-up outcomes Visual acuity}

The mean BCVA at baseline was $0.82 \pm 0.54$. After intravitreal bevacizumab, the mean BCVA was $0.62 \pm 0.37$ at 6 weeks, $0.54 \pm 0.33$ at 3 months, $0.45 \pm 0.27$ at 6 months, $0.45 \pm 0.25$ at 9 months, and $0.40 \pm 0.25$ at 12 months. The improvement in BCVA was statistically significant at each follow-up $(P<0.001)$ compared to baseline values (Figure 1$)$.

BCVA improved in $76 \%$ of the eyes, and more than three lines of improvement were seen in 55.5\%. BCVA was the same in $21 \%$ of the eyes, and it deteriorated in $3 \%$ at the 12-month follow-up.

\section{Subgroup analysis on visual outcome}

Further analysis was conducted to assess visual outcome at 12 months compared to the baseline values. The improvement in visual acuity was statistically significant in all cases, regardless of age at presentation being 59 years or less $(P<0.001)$ or more than 59 years $(P<0.001)$, whether there was concurrent systemic hypertension $(P<0.001)$, absence of hypertension $(P=0.01)$, duration of chief complain of less than 3 months $(P<0.001)$ or equal to or greater than 3 months $(P<0.001)$, grid laser $(P<0.004)$ or without grid laser $(P<0.001)$, and BCVA less than $1(P<0.001)$ or greater or equal to $1(P<0.001)$ (Table 2$)$.

\section{Central retinal thickness}

The mean CRT at baseline was $515.3 \pm 189.4 \mu \mathrm{m}$. The mean CRT was $340.4 \pm 135.6 \mu \mathrm{m}$ at 6 weeks, $265.8 \pm 123.9 \mu \mathrm{m}$ at 3 months, $244.4 \pm 126.7 \mu \mathrm{m}$ at 6 months, $241.2 \pm 109.3 \mu \mathrm{m}$

Table I General characteristics of patients

\begin{tabular}{lllll}
\hline & Minimum & Maximum & Mean & SD \\
\hline Age (years) & 28 years & 79 years & 58.22 years & 12.39 \\
$\begin{array}{l}\text { Duration of symptoms } \\
\text { prior to presentation }\end{array}$ & 0.2 & 6 & 2.8 & 1.8 \\
$\begin{array}{l}\text { (months) } \\
\text { Number of intravitreal } \\
\text { bevacizumab }\end{array}$ & 1 & 6 & 3.1 & 1 \\
injections & & & & \\
\hline
\end{tabular}

Abbreviation: SD, standard deviation. at 9 months, and $233.6 \pm 101.5$ at 12 months follow-up. A statistically significant reduction in CRT was observed at each follow-up visit $(P<0.001)$ relative to baseline values (Figure 2).

\section{Recurrent macular edema}

Recurrent ME was found in 19 cases (30.2\%) within the 12-month period. The rate of recurrent edema was not statistically different among the patients with presenting duration of greater than or less than 3 months $(P=0.979)$, presence or absence of concurrent systemic hypertension $(P=0.893)$, age less than or more than 59 years $(P=0.601)$, or BCVA at presentation $>1$ or less than or equal to $1 \operatorname{LogMAR}(P=0.44)$.

Including the 12-month follow-up, a total of 19 cases were treated with grid laser. In two cases, grid laser was administered twice. The grid laser was administered in one case at 2 months, in three cases at 3 months, in five cases at 4 months, in two cases at 5 months, in two cases at 6 months, in one case each at 7,8,9, and 10 months, and in two cases at 12 months.

Recurrent ME was found in $10.52 \%$ of cases at 3 months follow-up, $42.10 \%$ at 6 months follow-up, $26.3 \%$ at 9 months follow-up and $21.05 \%$ at 12 months follow-up. In one case, there was recurrent $\mathrm{ME}$ at 6 and 9 months follow-up, and in one other case there was recurrent edema at 4, 9, and 12 months follow-up. Persistent ME was present in two cases. Among the cases with recurrent ME, the repeat intravitreal bevacizumab was given in $6.4 \%$, combined intravitreal bevacizumab and grid laser in $4.9 \%$, grid laser only in $11 \%$, and was observed without intervention in $7.9 \%$ of cases.

\section{Safety}

In one case, the patient developed severe intraocular inflammation (uveitis) that was resolved with a topical steroid and cycloplegics. There were no other major ocular or systemic problems, such as increased intraocular pressure, endophthalmitis, retinal detachment, or thromboembolic events during the 12 months of follow-up.

\section{Discussion}

In our series of 63 BRVO eyes treated with intravitreal bevacizumab, ME and visual acuity significantly improved at the 12-month follow-up without any major ocular or systemic adverse effects. To our knowledge, this is one of the largest case series of BRVO patients that assesses the safety and effectiveness of intravitreal bevacizumab. 


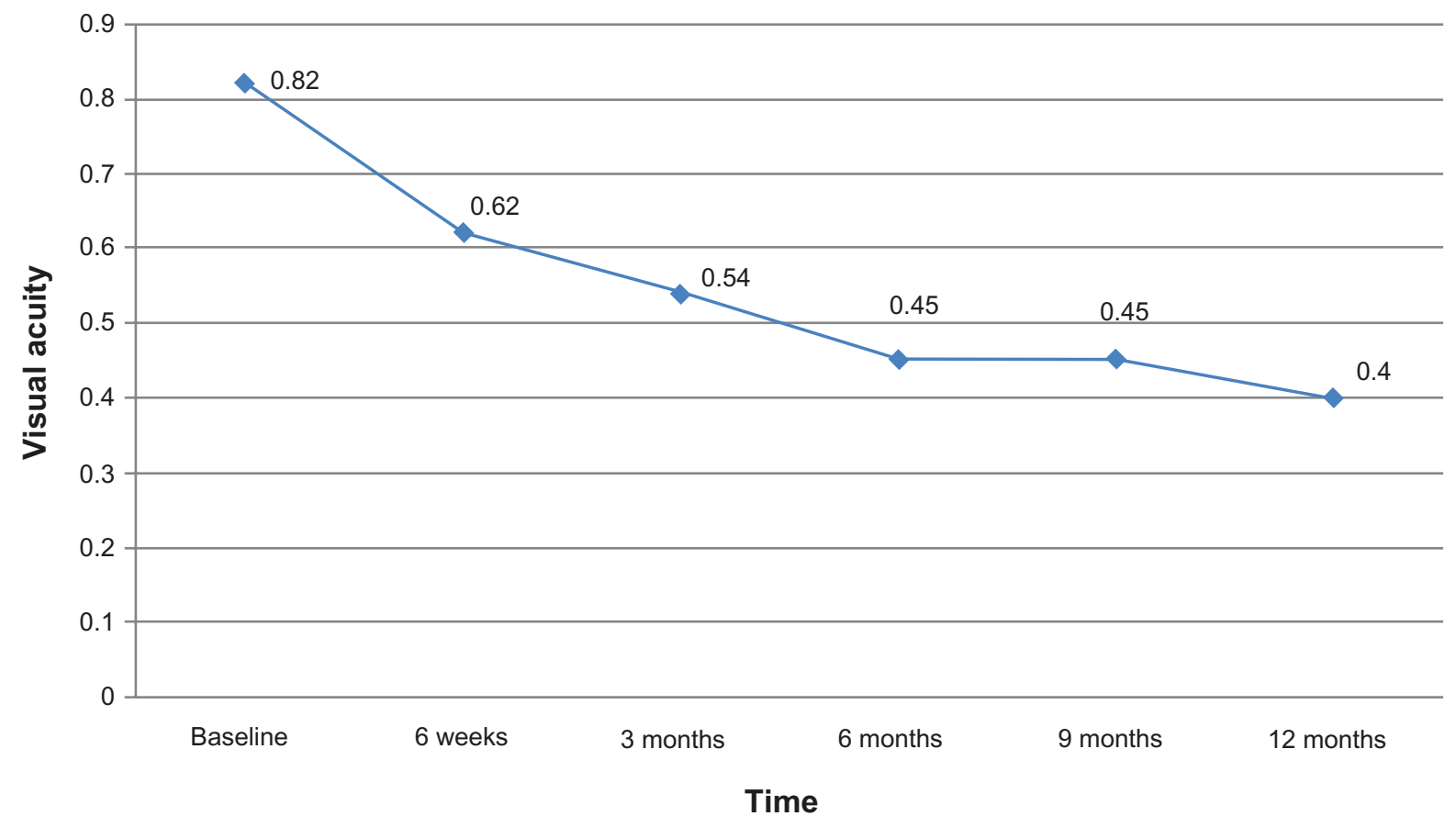

Figure I Status of best-corrected visual acuity after intravitreal bevacizumab.

The mean age of patients (58.22 years) and male predominance were consistent with the previous study on the demographic profile of RVO. ${ }^{1}$ The mean age was slightly higher than the series by Demir et $\mathrm{al}^{11}$ but was lower than the other published series. ${ }^{9-12}$ The male predominance in our case series could be due to the privilege of males in Nepalese society, which ensures better access to health facilities.

The average number of intravitreal bevacizumab in our series was 3.1, ranging from one to six injections. The average number needed was less in our series than in the other reported series at 12 months, ${ }^{10,11}$ but it was similar to the series by Ahmadi et al. ${ }^{12} \mathrm{ME}$, as assessed by CRT measurements, was significantly improved at each follow-up visit compared to baseline values. Our findings were consistent with other reported short- and long-term series. ${ }^{9-16}$ Nineteen cases (30.2\%) developed recurrent ME during a 1-year period, with slightly higher recurrence before 6 months. The addition of grid laser to recurrent cases with plenty of exudates may decrease recurrence after 6 months, but it needs further comparative study. Unlike other studies, we were not able to follow the patients at monthly intervals after the resolution of ME, which means we could have missed transient ME that may have subsided by the time of the next follow-up. In our series, there were no significant differences in the rate of recurrent ME among the cases with or without hypertension, duration of complaints longer or shorter than 3 months, age

Table 2 Visual outcome analysis at 12 months

\begin{tabular}{|c|c|c|c|c|}
\hline Characteristics & Number & $\begin{array}{l}\text { BCVA (LogMAR) at } \\
\text { presentation (mean/SD) }\end{array}$ & $\begin{array}{l}\text { BCVA (LogMAR) at } \\
12 \text { months (mean/SD) }\end{array}$ & $P$ value \\
\hline Age less than or equal to 59 years & 30 & $0.80(0.68)$ & $0.29(0.23)$ & $<0.001$ \\
\hline Age more than 59 years & 33 & $0.85(0.38)$ & $0.49(0.23)$ & $<0.001$ \\
\hline Presence of systemic hypertension & 39 & $0.83(0.44)$ & $0.4 I(0.27)$ & $<0.00$ I \\
\hline Absence of systemic hypertension & 24 & $0.82(0.69)$ & $0.38(0.22)$ & 0.01 \\
\hline Presenting duration less than 3 months & 33 & $0.75(0.39)$ & $0.42(0.26)$ & $<0.001$ \\
\hline Presenting duration greater than or equal to 3 months & 30 & $0.75(0.67)$ & $0.38(0.24)$ & $<0.001$ \\
\hline Cases with BCVA less than I LogMAR & 44 & $0.56(0.21)$ & $0.38(0.24)$ & $<0.001$ \\
\hline Cases with BCVA equal or greater than I LogMAR & 19 & $1.42(0.59)$ & $0.43(0.28)$ & $<0.001$ \\
\hline Grid laser: yes & 17 & $1.07(0.73)$ & $0.4 \mathrm{I}(0.26)$ & $<0.004$ \\
\hline Grid laser: no & 46 & $0.73(0.42)$ & $0.39(0.24)$ & $<0.001$ \\
\hline
\end{tabular}

Abbreviations: BVCA, best-corrected visual acuity; LogMAR, logarithm of minimum angle of resolution; SD, standard deviation. 


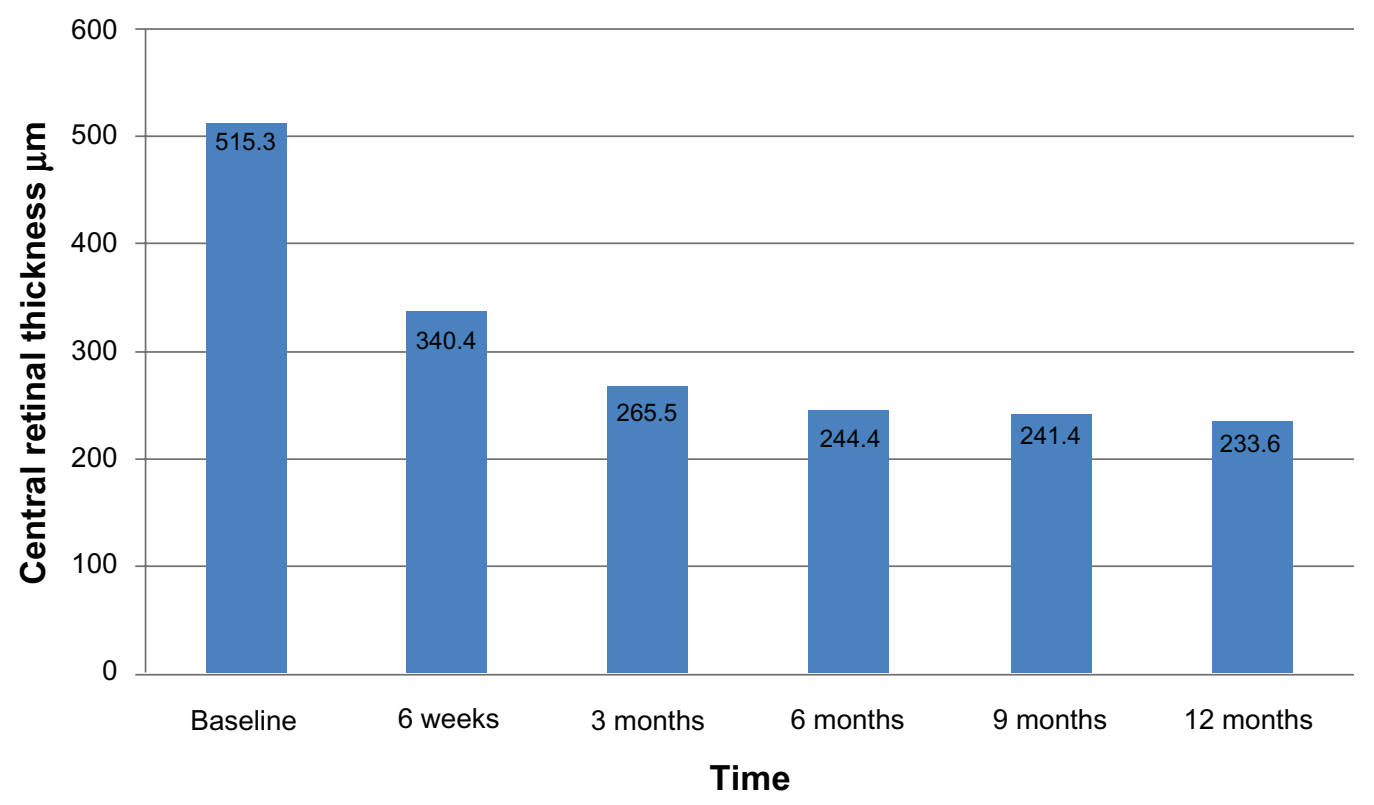

Figure 2 Status of central retinal thickness after intravitreal bevacizumab.

of the patient above or below 59 years, or BCVA less than 1 or greater than or equal to $1 \mathrm{LogMAR}$. Like the reduction in central macular thickness, BCVA also improved significantly in all follow-up visits, including the 12-month follow-up $(P<0.005)$. This finding in our series was consistent with

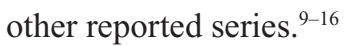

BCVA improved in more than four-fifths of the cases, with more than three lines of improvement in $55 \%$ of patients at the 12-month follow-up. In our series, BCVA improved significantly in all cases, without any differences among the groups regarding concurrent systemic hypertension, duration of the presentation (greater than or less than three months), grid laser or without grid laser, age group more than or less than 59 years, or presenting BCVA less than $<1$ or $\geq 1$ LogMAR. Our observation contradicts the findings of Ahmadi et al, ${ }^{12}$ who found that visual outcome was better among those without concurrent hypertension, in younger age groups, and with better presenting visual acuity.

As reported in other series, ${ }^{9-16}$ we did not observe any major ocular or systemic problems after intravitreal bevacizumab, such as endophthalmitis, cataract, glaucoma, retinal detachment, or thromboembolic events, except for one case of uveitis that was completely resolved with topical steroids and cycloplegics, with good visual recovery. Although intravitreal injections are routinely administered on an outpatient basis in developed countries, all of the intravitreal injections in our series were administered in the operating theater, using all appropriate aseptic precautions. Our safety results were consistent with other series from developed countries, so we cannot comment on intraocular infections as an outpatient procedure risk in developing countries such as Nepal. ${ }^{9-16}$

The other limitation was that, except for a few cases, fundus fluorescein angiography was not performed in our series at baseline or at follow-up visits to assess the change in capillary nonperfusion areas. Although this study confirms the effectiveness and safety of intravitreal bevacizumab as reported in other countries, it also provides guidelines for treating ME secondary to BRVO in countries like Nepal, which have limited resources.

Intravitreal bevacizumab is an effective and safe drug for reducing $\mathrm{ME}$ and improving visual acuity ${ }^{9-16}$ compared to intravitreal triamcinolone, which is more likely to raise intraocular pressure and enhance cataract formation, ${ }^{5,6}$ and relative to grid laser alone, which has limited potential for visual recovery. ${ }^{4}$ However, the main drawback of intravitreal bevacizumab is its short duration of action and recurrent ME. ${ }^{9-16}$

We recommend further long-term, randomized, case control studies of intravitreal bevacizumab, with or without addition of grid laser, for the role of grid laser in reducing recurrent ME and for long-term safety and effectiveness of intravitreal bevacizumab in the future.

\section{Conclusion}

Intravitreal bevacizumab appears to be an effective and safe drug for reducing $\mathrm{ME}$ and improving visual acuity secondary to BRVO during 12 months of follow-up at a hospital setting in a developing country, such as Nepal. 


\section{Acknowledgement}

The authors are grateful to Professor Dr Paul S Bernstein from the University of Utah, for final editing of this manuscript.

\section{Disclosure}

The authors report no conflicts of interest in this work.

\section{References}

1. Thapa R, Paudyal G, Bernstein PS. Demographic characteristics, patterns, and risk factors for retinal vein occlusion in Nepal: a hospital-based case-control study. Clinic Experiment Ophthalmol. 2010; 38(6):583-590.

2. Lim LL, Cheung N, Wang JJ, et al. Prevalence and risk factors of retinal vein occlusion in an Asian population. Br J Ophthalmol. 2008;92(10):1316-1319.

3. Klein R, Klein BE, Moss SE, Meuer SM. The epidemiology of retinal vein occlusion: The Beaver Dam Eye Study. Trans Am Ophthalmol Soc. 2009:98;133-141.

4. The Branch Vein Occlusion Study Group. Argon laser photocoagulation for macular edema in branch vein occlusion. Am J Ophthalmol. 1984: 98(3):271-282.

5. Hou J, Tao Y, Jiang YR, Li XX, Gao L. Intravitreal bevacizumab versus triamcinolone acetonide for macular edema due to branch retinal vein occlusion: a matched study. Chin Med J (Engl). 2009;122(22): 2695-2699.

6. Ip MS, Gottlieb JL, Kahana A, et al. Intravitreal triamcinolone for the treatment of macular edema associated with central retinal vein occlusion. Arch Ophthalmol. 2004;122(8):1131-1136.

7. Noma H, Minamoto A, Funatsu H, et al. Intravitreal levels of vascular endothelial growth factor and interleukin-6 are correlated with macular edema in branch retinal vein occlusion. Graefes Arch Clin Exp Ophthalmol. 2006;244(3):309-315.
8. Rosenfeld PH, Fung AE, Puliafito CA. Optical coherence tomography findings after an intravitreal injection of bevacizumab (Avastin) for macular edema from central vein occlusion. Ophthalmic Surg Lasers Imaging. 2005;36(4):336-339.

9. Rabena MD, Pieramici DJ, Castellarin AA, Nasir MA, Avery RL. Intravitreal bevacizumab (Avastin) in the treatment of macular edema secondary to branch retinal vein occlusion. Retina. 2007;27(4): 419-425.

10. Prager F, Michels S, Kriechbaum K, et al. Intravitreal bevacizumab (Avastin) for macular oedema secondary to retinal vein occlusion: 12-month results of a prospective clinical trial. Br J Ophthalmol. 2009;93(4):452-456.

11. Demir M, Oba E, Gulkilik G, Odabasi M, Ozdal E. Intravitreal bevacizumab for macular edema due to branch retinal vein occlusion: 12-month results. Clin Ophthalmol. 2011;5:745-749.

12. Ahmadi AA, Chuo JY, Banashkevich A, Ma PE, Maberley DA. The effects of intravitreal bevacizumab on patients with macular edema secondary to branch retinal vein occlusion. Can J Ophthalmol. 2009; 44(2):154-159.

13. Gutièrrez JC, Barquet LA, Caminal JM, et al. Intravitreal bevacizumab (Avastin) in the treatment of macular edema secondary to retinal vein occlusion. Clin Ophthalmol. 2008;2(4):787-791.

14. Abegg M, Tappeiner C, Wolf-Schnurrbusch U, Barthelmes D, Wolf S, Fleischhauer J. Treatment of branch retinal vein occlusion induced macular edema with bevacizumab. BMC Ophthalmol. 2008;8:18.

15. Figueroa MS, Contreras I, Noval CS, Arruabarrena C. Results of bevacizumab as the primary treatment for retinal vein occlusions. $\mathrm{BrJ}$ Ophthalmol. 2010;94(8):1052-1056.

16. Kriechbaum K, Michels S, Prager F, et al. Intravitreal Avastin for macular oedema secondary to retinal vein occlusion: a prospective study. Br J Ophthalmol. 2008;92(4):518-522.
Clinical Ophthalmology

\section{Publish your work in this journal}

Clinical Ophthalmology is an international, peer-reviewed journal covering all subspecialties within ophthalmology. Key topics include: Optometry; Visual science; Pharmacology and drug therapy in eye diseases; Basic Sciences; Primary and Secondary eye care; Patient Safety and Quality of Care Improvements. This journal is indexed on

\section{Dovepress}

PubMed Central and CAS, and is the official journal of The Society of Clinical Ophthalmology (SCO). The manuscript management system is completely online and includes a very quick and fair peer-review system, which is all easy to use. Visit http://www.dovepress.com/ testimonials.php to read real quotes from published authors. 